San Jose State University

SJSU ScholarWorks

Master's Theses

Master's Theses and Graduate Research

Spring 2017

\title{
The Moderating Role of Transformational Leadership and Perceived Organizational Support in the Relationship Between Openness to Experience and Creativity
}

Monica Luu

San Jose State University

Follow this and additional works at: https://scholarworks.sjsu.edu/etd_theses

\section{Recommended Citation}

Luu, Monica, "The Moderating Role of Transformational Leadership and Perceived Organizational Support in the Relationship Between Openness to Experience and Creativity" (2017). Master's Theses. 4809. DOI: https://doi.org/10.31979/etd.yqs2-e53k

https://scholarworks.sjsu.edu/etd_theses/4809

This Thesis is brought to you for free and open access by the Master's Theses and Graduate Research at SJSU ScholarWorks. It has been accepted for inclusion in Master's Theses by an authorized administrator of SJSU ScholarWorks. For more information, please contact scholarworks@sjsu.edu. 


\title{
THE MODERATING ROLE OF TRANSFORMATIONAL LEADERSHIP AND PERCEIVED ORGANIZATIONAL SUPPORT IN THE RELATIONSHIP BETWEEN OPENNESS TO EXPERIENCE AND CREATIVITY
}

\author{
A Thesis \\ Presented to \\ The Faculty of the Department of Psychology \\ San José State University \\ In Partial Fulfillment \\ of the Requirement for the Degree \\ Master of Science
}

by

Monica A. Luu

May 2017 
(C) 2017

Monica A. Luu

ALL RIGHTS RESERVED 
The Designated Thesis Committee Approves the Thesis Titled

THE MODERATING ROLE OF TRANSFORMATIONAL LEADERSHIP AND PERCEIVED ORGANIZATIONAL SUPPORT IN THE RELATIONSHIP BETWEEN OPENNESS TO EXPERIENCE AND CREATIVITY

by

Monica Luu

APPROVED FOR THE DEPARTMENT OF PSYCHOLOGY

SAN JOSÉ STATE UNIVERSITY

May 2017

Dr. Megumi Hosoda

Department of Psychology

Dr. Altovise Rogers

Department of Psychology

Ms. Taylor Gatti

Pacific Gas and Electric Company 


\title{
ABSTRACT \\ THE ROLE OF TRANSFORMATIONAL LEADERSHIP AND PERCEIVED ORGANIZATIONAL SUPPORT IN PREDICTING CREATIVITY
}

\author{
by Monica A. Luu
}

Although openness to experience has been found to be a consistent and important determinant of creativity, organizations have been interested in ways in which they could alter the environment in order to increase creativity. Woodman, Sawyer, and Griffin (1993) argue that organizational creativity is a function of the interaction between an individual's personality and environment. Using Woodman's theory, the present study was conducted to test whether two organizational factors, transformational leadership and perceived organizational support (POS), would moderate the relationship between openness to experience and creativity. Data were collected from 114 fulltime and parttime employees from various organizations through use of online surveys. Overall, although openness to experience, transformational leadership (in particular, articulating a vision), and POS were found to predict creativity, neither transformational leadership nor POS moderated the relationship between openness to experience and creativity. These findings suggest that (a) the more open to experience individuals are, (b) the more a leader articulates a vision, and (c) the more individuals perceive support from their organization, the more creativity individuals will exhibit. Organizations should therefore train their leaders to clearly articulate a vision and provide support to followers in order to increase employee creativity. 


\section{ACKNOWLEDGEMENTS}

I would like to thank my thesis committee for their unwavering support and numerous hours spent revising my thesis. I realize how busy everybody is, and I can't express how grateful I am for every hour spent reading and providing me invaluable feedback on my thesis. Megumi Hosoda, thank you for being my thesis chair and assisting, guiding, and motivating me in this year-long venture of writing my thesis. I would undoubtedly still be in the midst of writing my thesis without your patient and gentle guidance. Altovise Rogers, thank you for your insightful comments that implored me to delve deeper into my topic; your feedback encouraged me to gain a broader understanding of creativity and its correlates. Taylor Gatti, thank you for providing me advice and guidance throughout the whole program.

To my family and friends, thank you for continuously supporting me in my academic endeavors. Mom and Dad, thank you for being patient and having faith in me throughout my journey towards becoming a full-fledged adult. Without everybody's endless support, I would not have been able to achieve this accomplishment. 


\section{TABLE OF CONTENTS}

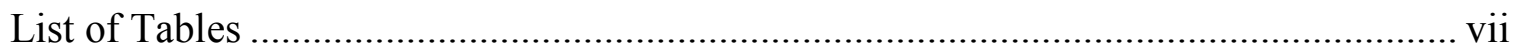

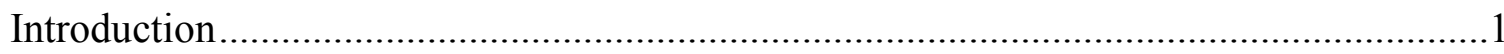

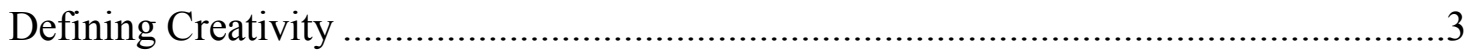

Previous Research on the Predictors of Creativity …….............................................. 4

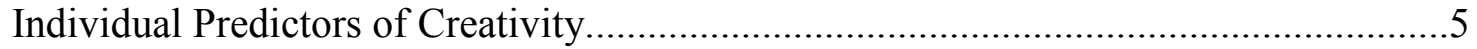

The five-factor model of personality ......................................................................

Openness to experience .......................................................................................

Organizational Predictors of Creativity ...............................................................

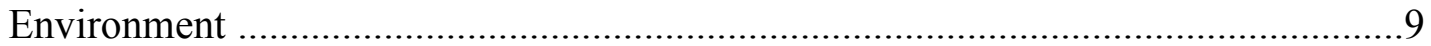

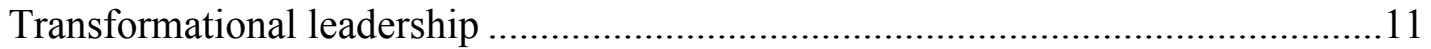

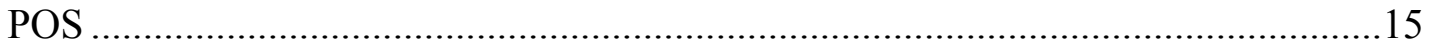

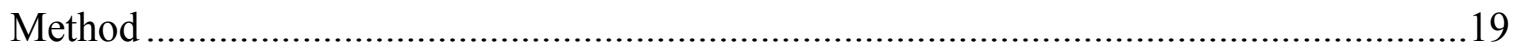

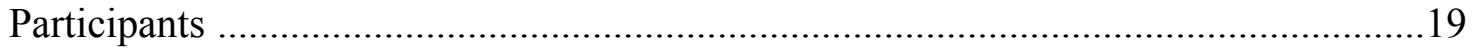

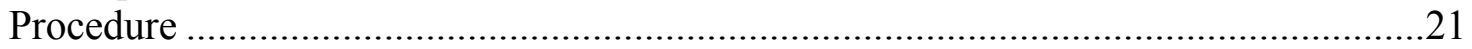

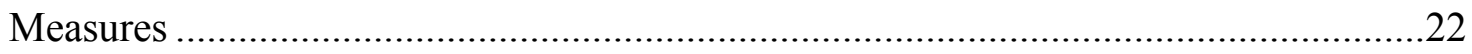

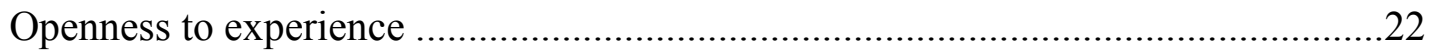

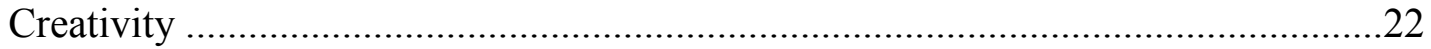

Transformational leadership ......................................................................2.

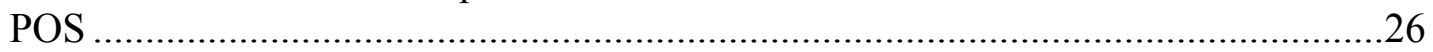

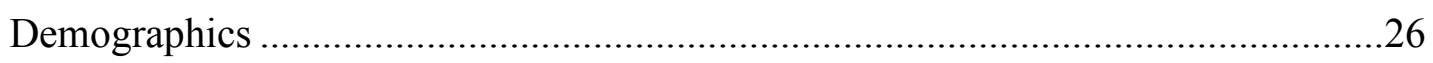

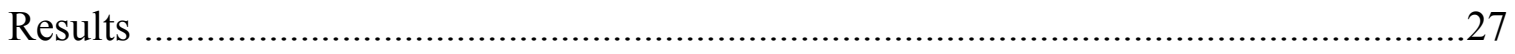

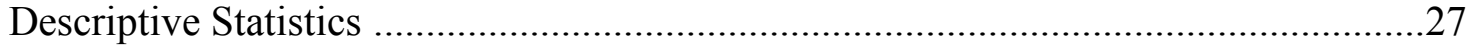

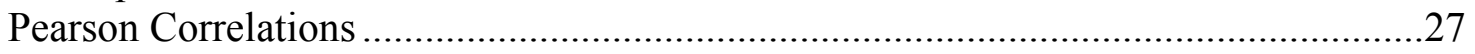

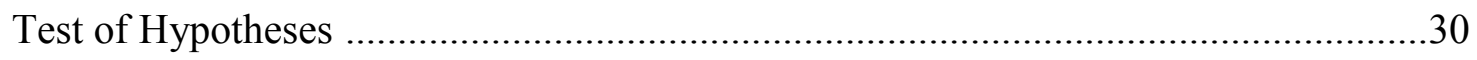

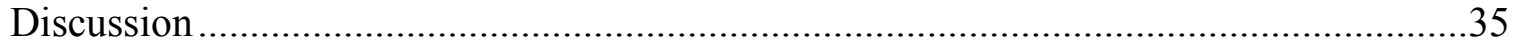

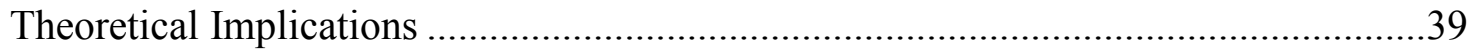

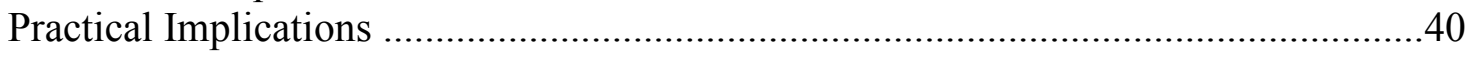

Limitations of the Study and Future Research .........................................................42

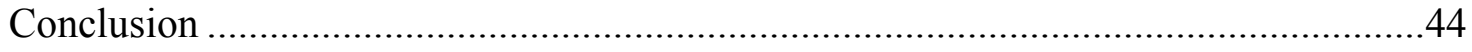

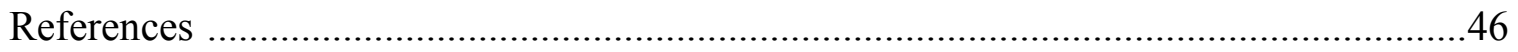

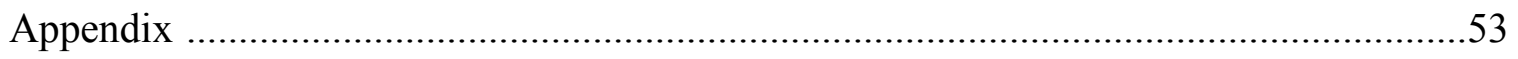




\section{LIST OF TABLES}

Table 1. Demographic Information of Participants................................20

Table 2. Summary of Exploratory Factor Analysis Results for Transformational Leadership Measure..................................................... 25

Table 3. Means, Standard Deviations, Pearson Correlations, and Cronbach's Alphas........................................................29

Table 4. Hierarchical Regression Analysis Summary for Transformational

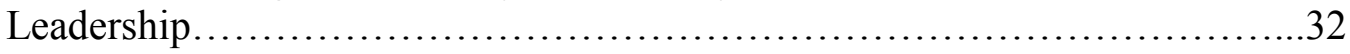

Table 5. Hierarchical Regression Analysis Summary for POS ........................ 34 


\section{Introduction}

Creativity, defined as the generation of novel and useful ideas, is intricately linked to innovation, the implementation of novel ideas (Amabile, 1996). The ability to laterally analyze a problem in order to craft solutions and ultimately innovate has proven to be increasingly vital to the long-term performance of a company (Klijn \& Tomic, 2010). Therefore, understanding the predictors of creativity as well as the factors that may influence the relationship between predictors and creativity is central to organizations that wish to compete within a rapidly changing global market.

What combination of factors facilitates creativity within the workplace? Researchers believe that creative behavior is a complex interaction between personal and situational factors (e.g. Amabile, 1988; Scott \& Bruce, 1994). Viewing creativity from this interactionist perspective, it is theorized that certain personality traits that predict creativity are linked to creative behavior to the extent that the situation allows for the manifestation of an individual's predisposition (George \& Zhou, 2001). In other words, certain factors within an environment, such as organizational factors, can be strongly influential in shaping the behavior of people (Davis-Blake \& Pfeffer, 1989). For example, situational constraints may reduce creative behavior within individuals who are high in openness to experience, a trait that is highly correlated with creativity and defined as receptiveness to novel and unconventional ideas (Furnham, Crump, Batey, \& ChamorroPremuzic, 2009). Research supports the notion that environmental factors rather than solely genetic factors play a large role in influencing an individual's creativity level 
(Kandler et al., 2016). In other words, even those who are low in openness to experience can develop their creativity levels when nurtured in the right environment.

Thus, understanding how certain organizational factors can encourage the manifestation of creative behavior is pertinent to increasing employee creativity. Specifically, what aspects of the organization can be altered in order to produce an environment that does not hamper an individual's creativity? Which organizational factors can facilitate creativity in those who are not naturally inclined to be creative or who are low in openness to experience? Research has revealed that both transformational leadership (Allen, Smith, \& Da Silva, 2013; Jung, 2001; Jung \& Avolio, 2000) and perceived organizational support (POS) (Amabile, Conti, Coon, Lazenby, \& Herron, 1996) are positively related to creativity. Transformational leaders and POS might encourage employees who are high in openness to experience to display their creative behavior and help employees who are low in openness to experience become more creative. In other words, these organizational factors might interact with personality traits to influence creativity.

There has yet to be a study that examines the influential effects that both transformational leadership and POS can have on the relationship between openness to experience and level of creativity. The purpose of this study was to examine whether transformational leadership and POS can moderate this relationship such that those who are low in openness to experience would exhibit enhanced creativity. Additionally, I examined under what conditions employee creativity is most likely to be at its highest. This was the first study examining transformational leadership and POS as moderators of 
the openness to experience and creativity relationship, therefore filling a gap within the creativity literature. The following sections define creativity and provide a review of the literature on the individual and organizational predictors of creativity. Additionally, these sections provide the rationale for transformational leadership and POS as moderators of the relationship between openness to experience and creativity and present the hypotheses that were tested.

\section{Defining Creativity}

What is creativity? And how is it different from innovation? Within the academic literature, creativity assumes two main definitions: the generation of novel and useful ideas (Amabile, 1996; Woodman, Sawyer, \& Griffin, 1993) and the cognitive process associated with the production of original ideas (Amabile, 1983). Because the first definition of creativity is most often used, the present study adopted the definition of creativity as the generation of novel and useful ideas.

Innovation is closely related to the concept of creativity and is defined as the successful implementation of novel ideas and solutions within an organization (Amabile, 1996). In other words, creativity focuses on production, whereas innovation focuses on execution. Although creativity can exist without innovation, innovation cannot exist without creativity. As the main building block of innovation, creativity as a research topic has continued to attract an increasing number of scholars (Sawyer, 2012). This trend demonstrates the desire for organizations to gain a more scientific understanding of both the individual and organizational factors that lead to creativity so that they may craft an environment that is conducive to fostering innovation. 


\section{Previous Research on the Predictors of Creativity}

In the past, research on creativity focused more heavily on the individual characteristics of a person than the characteristics of the environment as antecedents of creativity (Barron \& Harrington, 1981). However, more recently, researchers have studied creativity using an interactionist approach, which posits that creative behavior is a result of a rather complex interaction between individual and environmental factors (Oldham \& Cummings, 1996). These factors continuously work in tandem to produce a certain behavior. For example, although an individuals may be creative, they will only exhibit creative behavior to the extent that situational factors support and facilitate such behavior. Given this view on creativity, rather than examining purely individual factors, researchers have begun investigating the impact of environmental factors, particularly those within a business organization, on creativity within a person (Amabile, 1996). Examples of such organizational factors are leadership style (Cohen, 2005), POS (Amabile et al., 1996), and organizational justice (Clark \& James, 1999; George \& Zhou, 2007). Furthermore, recent research has been exploring organizational factors as potential mediators or moderators of the relationship between individual predictors and creativity (e.g., Carmeli, Sheaffer, Binyamin, Reiter-Palmon, \& Shimoni, 2014; Hermann \& Felfe, 2013).

In order to determine (a) the individual predictor that has the strongest relationship to creative behavior and (b) the organizational factors that best allow for creative behavior to manifest, I reviewed prior literature for both theoretical and empirical evidence. In the following section, I present research that explores the five-factor model of personality's 
relation to creativity and ultimately supports my usage of openness to experience as the individual predictor that has the strongest relationship to creativity.

\section{Individual Predictors of Creativity}

The five-factor model of personality. Research has consistently revealed that personality is related to creativity (Batey \& Furnham, 2006). A widely used personality model within both personality and organizational research is the five-factor model, which consists of the Big Five personality traits: openness to experience, conscientiousness, extraversion, agreeableness, and neuroticism (e.g. Barrick \& Mount, 1993; Wiggins \& Trapnell, 1997). Many researchers have explored which of these five traits is most related to creativity.

Prior research has shown that the method used to measure creativity has a substantial impact on which of these five personality traits are related to creativity. Many creativity studies have tackled the topic using a multi-trait multi-method approach, whereby multiple predictors (in this case, the Big Five personality traits) are examined using a series of different measures of creativity (Batey \& Furnham, 2010). Common measures of creativity include assessing an individual's ability to generate different ways in which an object can be used (Divergent Thinking [DT] Fluency) as well as the quality of these solutions (Rated DT), self-report measures in which the individual either assesses his or her own creativity (Self-Rated Creativity) or lists his or her creative achievements (Inventory of Creative Achievement), and the combination of these four measures in order to create a composite creativity score. 
The relationship between the Big Five personality traits and creativity is less clearly established when using measures of DT Fluency and Rated DT. Although Batey, Furnham, and Safiullina (2010) found no relationship between all five personality traits and creativity, other researchers found both positive and negative relationships between certain personality traits and creativity. For example, when using a DT Fluency measure, openness to experience and extraversion were positively related to creativity, although agreeableness was negatively related (Batey, Chamorro-Premuzic, \& Furnham, 2009; Chamorro-Premuzic \& Reichenbacher, 2008; Furnham \& Bachtiar, 2008; Furnham, Batey, Anand, \& Manfield, 2008). When using a Rated DT measure, openness to experience and extraversion were found to be positively related to creativity, whereas both agreeableness and neuroticism were negatively related to creativity (Furnham et al., 2009).

However, when using the Inventory of Creative Achievement and self-rated creativity measures, a clear relationship between personality traits and creativity emerged. For example, openness to experience (Batey et al., 2010; Batey \& Furham, 2006; Carson, Peterson, \& Higgins, 2005; Furnham \& Bachtiar, 2008; Furnham et al., 2008) and extraversion (Carson et al., 2005; Furnham \& Bachtiar, 2008; Furnham et al., 2008) were positively related to scores in the Inventory of Creative Achievement. Measures of SelfRated Creativity similarly revealed a positive relationship between creativity and openness to experience (Batey et al., 2010; Furnham et al., 2008) and extraversion (Furnham \& Bachtiar, 2008). 
Results of a meta-analysis by Feist (1998), who analyzed a total of 83 studies that compared creative people to non-creative people based on their personality traits (i.e. scientists versus non-scientists, creative versus less creative scientists, and artists versus non-artists), supported that openness to experience, extraversion, and neuroticism were positively correlated with creativity, whereas conscientiousness and agreeableness were negatively correlated. Based on these results, Feist concluded that creative people were "more open to new experiences, less conventional and less conscientious, more selfconfident, self-accepting, driven, ambitious, dominant, hostile, and impulsive" (p. 290).

Although both openness to experience and extraversion were found to be reliable predictors of creativity, regardless of the creativity measure used, I examined the relationship between openness to experience and creativity rather than extraversion and creativity. This is because the correlation between extraversion and creativity is not as strong as that of openness to experience and creativity (Furnham et al., 2009). Thus, it would be beneficial for organizations to establish various methods, such as modifying aspects of the organizational environment, in order to increase the creativity level of those who are low in openness to experience. The following section provides additional rationale to support the link between openness to experience and creativity.

Openness to experience. Openness to experience, defined as the proactive search for novel experiences, is composed of six different facets: active imagination, aesthetic sensitivity, attentiveness to inner feelings, preference for variety, intellectual curiosity, and attentiveness to values. Those who are open to new experiences are described as amenable to new ideas and thus more likely to hold an unconventional perspective; those 
who are not open to new experiences are described as conventional and thus more likely to prefer familiar routines over novelty (Costa \& McCrae, 1992). The role of openness to experience in relation to creativity has been well established in the literature (e.g. Batey et al., 2010; Carson et al., 2005; Furnham \& Bachtiar, 2008).

How does openness to experience enhance the creativity of an individual, particularly within an organizational setting? Those who attune to novelty and are naturally inclined towards variety are more prone to thinking outside of the given boundaries as opposed to adhering to the status quo (McCrae \& Costa, 1997). This particular mindset would facilitate the creation of novel approaches in order to achieve task objectives and improve performance. Additionally, those who are high in openness to experience possess a larger range and depth of experience that they can draw from when brainstorming ideas (McCrae, 1996). This experiential variety serves as a large pool of knowledge to draw from, thus allowing for individuals to extract knowledge from one area and apply it to another vastly different area. The intersection of two different areas often produces new perspectives from which to view a situation, and those who are high in openness to experience, due to their appreciation of new ways of approaching things as well as their greater sensitivity to having new experiences, are more likely to make these connections (Costa \& McCrae, 1992). Alternatively, those who are low in openness to experience are less likely to immerse themselves in a variety of areas and more likely to adhere to conventional methods and an established routine, therefore decreasing the likelihood that they would create novel ways to approach a familiar problem. 
However, one can imagine a situation in which individuals who are high in openness to experience and therefore predisposed to creativity might exhibit low creativity due to situational constraints that inhibit expression of their potential. In order for the creative potential of an individual to properly manifest, the organizational environment must possess characteristics that promote his/her predisposition to be creative. Thus, for the following sections of this paper I assess which organizational factors can be altered in order to increase the creativity levels of employees who are low in openness to experience. In the following sections, I present research that reviews the importance of environment in enhancing creativity, the different facets of an organization that play an influential role on creativity, and specifically why transformational leadership and POS are two key aspects that may increase employee creativity.

\section{Organizational Predictors of Creativity}

Environment. The role of the environment in affecting the manner in which personality traits manifest has been well explored in the field of psychology. The theory of interactionism (Mead, 1934) was developed in order to explain why a person's behavior varies across situations. Interactionism assumes that behavior is directed by a combination of internal and external factors and that there is a reciprocal influence between individuals and the situations they encounter. Individuals choose a situation, and, according to their interpretation of the situation, they behave accordingly, which in turn affects the situation and its meaning (Endler \& Mogusson, 1976). Mathematically, this would be represented by the following formula: $\mathrm{B}=\mathrm{f}(\mathrm{P} \times \mathrm{E})$; behavior $(\mathrm{B})$ is a function of the interaction between personality variable $(\mathrm{P})$ and the situation the person is 
in $(E)$, where the effect of the situation depends on the type of person who is in it (Lewin, 1940). Stemming from interactionism, the interactionist model of organizational creativity was developed by Woodman et al. (1993) to explain how creative behavior in an organization is a function of the interaction between individuals' predisposition and their environment.

Research within social psychology also supports the impact of the environment on personality, often through comparing and contrasting identical and fraternal twins who were reared together or apart. Kandler et al. (2016), using a classical twin design, analyzed identical and fraternal twins who were reared together to determine the degree to which creativity levels stemmed from genetic or environmental factors. Results showed that perceived creativity (creativity measured through self- and peer-reports) and tested figural creativity (creativity measured through ability tests) had heritability estimates of $62 \%$ and $26 \%$, respectively. This highlights the underlying notion that although a genetic component of creativity undoubtedly exists, not all individual differences in creativity can be explained solely by genetic means; rather, environmental influences are also responsible for differences in creativity levels. Other researchers have also identified the environment as a critical way in which creative behavior develops (eg., Amabile, 1983; Sternberg, 2006).

Although different studies have examined varying aspects of the organization in their quest to understand the environmental dimensions that affect employee creativity, Moghimi and Subramaniam (2013) and Hunter, Bedell, and Mumford (2007) underscored the need for the following four facets to be present within an organization in 
order to encourage creative behavior within employees: support (the degree to which an organization and/or leader supports employees), mission clarity (the awareness of organizational goals regarding creativity), intellectual stimulation (the provision of an environment in which employees feel sufficiently challenged), and resources (the perception that the organization is willing to provide the means to facilitate creative behavior). How should organizations go about structuring these four aspects of the organization in order to create an environment that facilitates creativity? To address these facets, organizations can train supervisors how to lead using a transformational leadership style and increase their employees' POS.

Transformational leadership. Research has continually supported the notion that the style in which a supervisor chooses to lead can substantially influence creativity within employees (Cohen, 2005). Particularly, positive leadership, which infuses the ideas of positive psychology into a leadership style that is designed to encourage a positive psychological state, can affect the organizational culture and the creative behavior within the workplace (Cohen-Meitar, Carmeli, \& Waldman., 2009). Examples of positive leadership theories include transformational leadership theory, authentic leadership theory, charismatic leadership theory, and altruistic leadership theory (Donaldson \& Ko, 2010).

Of the myriad leadership theories within the literature, transformational leadership has been shown to be a vital indicator of an organizational environment (Jung, Chow, \& $\mathrm{Wu}, 2003)$; a transformational leader can cultivate an innovative environment that promotes employee creativity (Jaiswal \& Dhar, 2015). Recognized as the main driving 
force of employees' creativity and innovation (Nusair, Ababneh, \& Bae, 2012), transformational leaders provide an environment in which employees feel safe to think creatively and view old problems from the vantage point of a new perspective (Gumusluoglu \& Ilsev, 2009). Although some studies do not support the positive relationship between transformational leadership and creative behavior (Jaussi \& Dionne, 2003; Kahai, Sosik, \& Avolio, 2003), the positive consequences of transformational leadership on employee creative behavior have been well documented in many other studies (Allen et al., 2013; Jung, 2001; Jung \& Avolio, 2000; Shin \& Zhou, 2003; Gumugluoglu \& Islev, 2009).

The most commonly used theoretical framework of transformational leadership is Bass's transformational leadership theory (1985), which consists of four dimensions: idealized influence, inspirational motivation, intellectual stimulation, and individualized consideration (Bass, 1985). According to Judge and Piccolo (2004), the dimensions are defined as the following:

Idealized influence is the degree to which the leader behaves in admirable ways that cause followers to identify with the leader. Inspirational motivation is the degree to which the leader articulates a vision that is appealing and inspiring to followers. Intellectual stimulation is the degree to which the leader challenges assumptions, take risks, and solicits followers' ideas. Individualized consideration is the degree to which the leader attends to the follower's needs, acts as a mentor or coach to the follower, and listens to the follower's concerns and needs. (p. 755)

However, through a review of the extant literature, Podsakoff, MacKenzie, Moorman, and Fetter (1990) believe that transformational leadership consists of at least six rather than four dimensions: articulating a vision, providing an appropriate model, fostering the acceptance of group goals, high performance expectations, providing individualized 
support, and intellectual stimulation. The main difference between these two models is the addition of two dimensions, fostering the acceptance of group goals and high performance expectations, as articulating a vision and providing an appropriate model can be seen as equivalent to inspirational motivation and idealized influence, respectively. Fostering the acceptance of group goals is the degree to which leaders promote cooperation among employees and encourage employees to work towards a common goal, whereas high performance expectations is the degree to which leaders' behavior demonstrates that they expect excellence, quality, and high performance from their followers. Although our understanding of the dimensions involved in transformational leadership is still somewhat unclear, one thing that is unambiguous is transformational leadership's multidimensional nature.

Viewing transformational leadership as multidimensional and creative behavior as an interaction between the person and environment, in what specific ways might transformational leaders encourage creativity among employees? According to prior research, a leader's support, mission clarity (Moghimi \& Subramaniam, 2013) and intellectual stimulation (Hunter et al., 2007) are all aspects of an organization that positively impacted creative behavior within employees. When leaders provide support, clarify the organizational mission, and intellectually stimulate their followers, creative behavior is enhanced. A supervisor who adapts a transformational leadership style can contribute to the fulfillment of these three aspects.

Through individualized consideration, employees will experience an increased sense of leader support due to the leader's ability to address their individual needs and 
concerns. The added support will increase the trust that employees have for their leaders (Bennis \& Nanus, 1985), creating an environment in which workers feel safe to take risks, such as trying a new method to approach a problem despite being unsure of the results. Consequently, employees will alter their attitudes to be less risk averse and thus more open to creative and innovative work processes (Den Hartog, 2003).

A transformational leader can intellectually stimulate followers by being openminded to challenges, employee suggestions, and alternate ways in which a task can be accomplished rather than depriving employees of the cognitive resources needed to feel adequately challenged. The open-mindedness of a leader in turn challenges employees to adapt the same mentality by seeking novel ways to complete their task and challenging the status quo (Yunus \& Anuar, 2012). Additionally, intellectual stimulation helps employees gravitate "towards a creative synthesis by generating various possible solutions" (Bass, 1988, p. 29).

The sense of trust that employees feel around a transformational leader (Bennis \& Nanus, 1985) may also increase the ease in which they approach their supervisor with questions, therefore making it more likely that they will seek clarification of task and mission objectives when confused. Particularly, if the goals of the organization relate to creativity, a transformational leader will be able to explicitly clarify this to employees as well as inspire and motivate workers to improve their performance in a way that aligns with the organization's creativity goals (Podsakoff et al., 1990).

Using the interactionist model of creativity (Woodman et al., 1993), openness to experience may interact with transformational leadership to affect creativity. 
Transformational leaders can aid followers in enhancing their creativity levels by providing them with (a) the supportive environment that emboldens them to take risks, (b) intellectual stimulation that challenges them to seek novel ways to complete their tasks, and (c) an increased sense of trust that will encourage workers to seek clarification when confused about mission objectives. Thus, transformational leaders can cultivate an environment that allows those predisposed to creativity to display their full potential while inspiring those who are not predisposed to creativity to engage in more creative behavior. Although individuals who are low in openness to experience may initially find a creative task stressful, added support from a transformational leader may alleviate stress and alternatively motivate them to be more creative. In time, the continuous interaction between the person and a supportive environment may lead to the development of a more creative mindset. Thus, I hypothesized the following:

Hypothesis 1: Transformational leadership will moderate the relationship between openness to experience and creativity such that the relationship will be stronger when transformational leadership is high than when transformational leadership is low.

POS. POS is defined as the extent to which employees perceive their organization to be available to provide them with the resources required in order to efficiently complete their job and to manage stressful situations (George, Reed, Ballard, Colin, \& Fielding, 1993). POS has received attention from researchers as a possible method to increase positive work outcomes. For example, POS has been found to be related to organizational commitment, job involvement, strains, desire to remain, and withdrawal behavior such that those who perceive support from their organization are more committed to the 
organization, more involved with their job, and less prone to job-related strains and withdrawal behavior (Rhoades \& Eisenberger, 2002). Eisenberger and Stinglmanber (2011) also found that, among the many positive consequences of POS, such as work engagement, counterproductive work behavior, safety-related behaviors, customer service, and emotional labor among service; creativity and innovation were also positively related to POS.

Other researchers have also supported the notion that a higher degree of POS results in increased creative behavior within employees (Amabile et al., 1996; Bammens, Notelaers, \& Van Gils, 2013; Scott \& Bruce, 1994). Scott and Bruce (1994) found that POS facilitated creative behavior within employees due to their perception of less risk, in addition to enhanced trust in the organization. However, Khazanchi and Masterson (2011) found no relationship between POS and creativity.

Yu and Frenkel (1994) explored the three components of POS theory as possible mediators of the POS and creativity relationship. According to POS theory, there are three mechanisms through which POS increases positive work outcomes: felt obligation, group identification, and outcome expectancy (Rhoades \& Eisenberger, 2002). Felt obligation, which is derived from social exchange theory, operates on the concept of mutual exchange; in other words, employees feel a duty to reciprocate any favorable treatment received from the organization through work behavior that positively benefits the organization (Gouldner, 1960). Group identification, which is derived from social identity theory, suggests that the respect received from the organization fulfills the employees' socio-emotional needs, therefore, enhancing their sense of identification with 
the organization and its goals (Ashforth \& Mael, 1989). Lastly, outcome expectancy, which is derived from expectancy theory, states that employees develop trust for the organization when cared for, thus strengthening their beliefs that they will be properly compensated for their hard work (Heslin, 2005).

Yu and Frenkel (2013), seeking to understand which of the three mechanisms of POS enhanced creativity, found that group identification and outcome expectancy were positively related to creative behavior and thus, effectively mediated the relationship between POS and creativity, whereas felt obligation solely increased task performance but not creative performance. This corresponds with self-determination theory, which asserts that autonomous motivation stems from satisfying the innate psychological needs of relatedness, autonomy, and competence (Deci \& Ryan, 1980); group identification would fulfill needs of relatedness and autonomy, whereas outcome expectancy would fulfill needs of competence and autonomy. This is also consistent with Sheldon and Elliot's (1998) finding that creativity is enhanced when work is intrinsically satisfying and workers personally identify with their work, whereas creativity is hampered when work is completed purely for external reasons, such as extrinsic rewards or social pressure.

Thus, POS might help employees who are low on openness to experience to become more creative by (a) increasing their trust that the organization will properly compensate them for hard work and (b) enhancing their sense of identification with the organization. If the organization emphasizes the goals of creativity and innovation, employees will align their own goals to that of the organization to the extent that they identify with the 
organization. The belief that any work that aids the organization will be recognized and rewarded will further drive employees to practice creative behavior. Furthermore, the perception of support from one's organization fulfills a basic prerequisite of creativity, as support would not only provide employees with the resources to successfully accomplish their task but also with the autonomy to complete the task using their own methods, thus leading to feelings of personal identification with their work.

Using the interactionist model of creativity (Woodman et al., 1993), openness to experience might interact with POS to affect creativity. Although individuals who are low in openness to experience and therefore not predisposed to being creative may initially find a creative task stressful, additional support from the organization may alleviate stress and alternatively motivate them to be more creative. In time, the continuous interaction between the person and a supportive environment may lead to the development of a more creative mindset. Additionally, those who are high in openness to experience and therefore predisposed to creativity may not display their creative potential if the organization is not supportive of such pursuits. Thus, I hypothesize the following:

Hypothesis 2: POS will moderate the relationship between openness to experience and creativity such that the relationship will be stronger when POS is high than when POS is low. 


\section{Participants}

\section{Method}

A total of 134 individuals participated in this study. However, due to the substantial amount of incomplete data, 20 participants were eliminated from the analysis. Thus, the final sample consisted of 114 respondents. The demographic information of these participants is reported in Table 1. The sample consisted of 43 males (37.7\%) and 61 females $(53.5 \%)$, with 10 respondents not reporting their gender. In terms of age, the majority of participants were between the ages of 18 and $34 ; 59.6 \%$ of them were ages $25-34$, and $30.7 \%$ were ages $18-24$. The other 10 participants were above the age of 34, with 1 participant not reporting his or her age.

Half of the participants identified themselves as Asian (50\%), followed by White/Caucasian (33.3\%), Hispanic/Latino (14\%), Black/African American (4.4\%), and American Indian/Alaskan Native (0.9\%). Many graduated from college, with over half holding a bachelor's degree (52.6\%) and 21.9\% holding either a master's or doctoral degree. Many participants worked at their current company for less than 3 years; 50 (43.9\%) reported being with their current organization for less than a year, and 34 (29.8\%) reported 1 - 3 years. A large majority did not hold a managerial position $(81.6 \%)$. 
Table 1

Demographic Information of Participants $(N=114)$

\begin{tabular}{|c|c|c|}
\hline Variable & $n$ & $\%$ \\
\hline \multicolumn{3}{|l|}{ Gender } \\
\hline Men & 43 & 37.7 \\
\hline Women & 61 & 53.5 \\
\hline \multicolumn{3}{|l|}{ Age } \\
\hline $18-24$ years & 35 & 30.7 \\
\hline $25-34$ years & 68 & 59.6 \\
\hline $35-44$ years & 3 & 2.6 \\
\hline $45-54$ years & 3 & 2.6 \\
\hline $55-65$ years & 3 & 2.6 \\
\hline Over 65 years & 1 & 0.9 \\
\hline \multicolumn{3}{|l|}{ Ethnicity } \\
\hline American Indian/ Alaskan Native & 1 & 0.9 \\
\hline Asian & 57 & 50.0 \\
\hline Black/ African American & 5 & 4.4 \\
\hline Hispanic/ Latino & 16 & 14.0 \\
\hline Caucasian/ White & 38 & 33.3 \\
\hline \multicolumn{3}{|l|}{ Education } \\
\hline High school degree & 2 & 1.8 \\
\hline Some college & 17 & 14.9 \\
\hline Graduated from college & 60 & 52.6 \\
\hline Advanced degree & 25 & 21.9 \\
\hline \multicolumn{3}{|l|}{ Years at Organization } \\
\hline Under 1 year & 50 & 43.9 \\
\hline $1-3$ years & 34 & 29.8 \\
\hline $3-5$ years & 11 & 9.6 \\
\hline $5-7$ years & 4 & 3.5 \\
\hline $7+$ years & 6 & 5.3 \\
\hline \multicolumn{3}{|l|}{ Position } \\
\hline Managerial position & 11 & 9.6 \\
\hline Non-managerial position & 93 & 81.6 \\
\hline
\end{tabular}




\section{Procedure}

The survey was electronic and created using Qualtrics; it was administered online and distributed via a link using my personal and professional networks, such as email and Facebook. Additionally, using the snowballing technique, participants were asked to distribute the link to their families, friends, or other working individuals. The survey invitation informed participants that I was collecting data to complete my thesis for my graduate program, and the survey would take fewer than 15 minutes to complete. I then thanked them for their time.

Upon clicking the survey link, participants were directed to a consent form that detailed the specifics of the survey. This consent form stated that the survey intended to measure their openness to experience and creativity levels, perception of support from organization, and supervisor's leadership behaviors. In addition to being ensured that all responses would remain confidential and participation was voluntary, participants were also provided with contact information if they had additional questions or concerns pertaining to the contents of the survey.

At the end of the consent form, participants were asked to select either "I consent" or "I do not consent." If participants chose the latter option, their web browser was directed to the end of the survey, where I thanked them for their time. If participants chose the former option, they were directed to the first page of the survey, where questions regarding the research began. Participants were asked to answer questions regarding their creativity level on the job, the level of transformational leadership qualities that their 
supervisor displayed, the extent to which they perceived their organization to be supportive of them, their openness to experience level, and demographics.

\section{Measures}

All scales used a 7-point Likert format ( $1=$ Strongly Disagree, $7=$ Strongly Agree $)$ unless otherwise noted. All items are listed in the Appendix. The items within each measure were averaged to create a composite score.

Openness to experience. Openness to experience was measured using the Big Five Inventory, which was developed by John and Srivastava (1999). Although this scale originally contained 44 items measuring 5 personality traits (openness to experience, conscientiousness, extraversion, agreeableness, and neuroticism), I only used the 10 items pertaining to openness to experience. The items measured the degree to which individuals were curious, imaginative, unconventional, aesthetically inclined, excitable, and broad in interest. Sample items include "Is original and comes up with new ideas" and "Values artistic, aesthetic experiences." A higher score is indicative of an individual who is more open to novel experiences. Cronbach's alpha was .83 , indicating high reliability.

Creativity. Creativity was measured using a 13-item scale developed by George and Zhou (2013). The items measured the degree to which individuals displayed creative behavior on the job. Sample items include "I will suggest new ways to increase quality" and "I will develop adequate plans and schedules for the implementation of new ideas." A higher score indicated that the participant displayed higher creativity levels on the job. Cronbach's alpha was .93 , indicating high reliability. 
Transformational leadership. Transformational leadership was measured using a 20-item scale developed by Podsakoff et al. (1990). The items represented the six main qualities possessed by transformational leaders: articulating a vision, providing an appropriate model, fostering acceptance of group goals, setting expectations of high performance, giving individualized support, and providing intellectual stimulation.

A principal components analysis with varimax rotation was conducted to verify the number of dimensions within this scale. The number of factors was forced to be six. Results showed that the items loaded on their respective dimensions. As can be seen in Table 2, only items 3 and 4 loaded both on articulating a vision and providing an appropriate model. However, I kept them in their original dimension, articulating a vision. The total variance accounted for was $79.38 \%$.

A higher score in a particular dimension indicated that participants perceived their supervisor as possessing more of that particular transformational leadership quality. Articulating a vision was measured with four items. Sample items include "Has a clear understanding of where we are going" and "Paints an interesting picture of the group for our future." Cronbach's alpha was .87 , indicating high reliability. Providing an appropriate model was measured with three items. Sample items include "Leads by 'doing,' rather than simply by 'telling", and "Provides a good model for me to follow." Cronbach's alpha was .93 , indicating high reliability. Fostering acceptance of group goals was measured with three items. Sample items include "Gets the group to work together for the same goal" and "Develops a team attitude and spirit among employees." Cronbach's alpha was .86, indicating high reliability. Setting expectations of high 
performance was measured with three items. Sample items include "Insists on only the best performance" and "Will not settle for second best." Cronbach's alpha was .83, indicating high reliability. Giving individualized support was measured with three items. Sample items include "Shows respect for my personal feelings" and "Behaves in a manner thoughtful of my personal needs." Cronbach's alpha was .85 , indicating high reliability. Intellectual stimulation was measured with four items. Sample items include "Asks questions that prompt me to think" and "Has stimulated me to rethink the way I do things." Cronbach's alpha was .88 , indicating high reliability. 

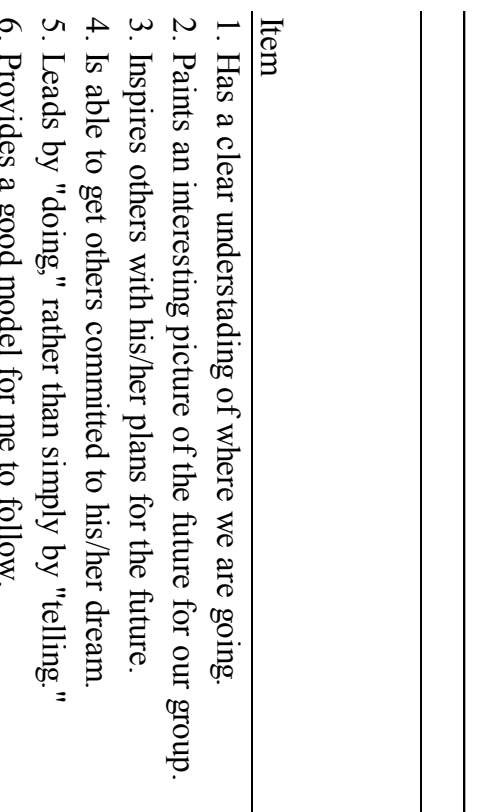

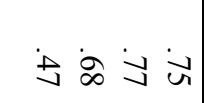


POS. POS was measured using a shortened 8-item version of the Survey of Perceived Organizational Support, which was developed by Eisenberger, Huntington, Hutchison, and Sowa (1986). Although the original scale consisted of 36 items, the shortened version consisted of only the items that had the highest loadings. The items measured the extent to which individuals perceived their organization to value their contribution and care about their well-being. Sample items include "My organization considers my goals and values" and "Help is available from my organization when I have a problem." A higher score indicated that the participants perceived their organization to be supportive. Cronbach's alpha was .90 , indicating high reliability.

Demographics. Participants were asked to answer seven demographic questions regarding their age, ethnicity, gender, level of education, tenure at the current organization, and current position. They were also asked if they supervised other individuals. 


\section{Results}

\section{Descriptive Statistics}

The means and standard deviations were calculated for the measured variables (see Table 3). Participants, on average, were open-minded to new experiences $(M=5.13$, $S D=0.84)$ and displayed high creativity on the job $(M=5.37, S D=0.88)$. They moderately agreed that their supervisor displayed all six transformational leadership qualities: articulating a vision $(M=4.85, S D=1.23)$, providing an appropriate model $(M=4.98, S D=1.48)$, fostering acceptance of group goals $(M=5.35, S D=1.19)$, setting expectations of high performance $(M=5.08, S D=1.21)$, giving individualized support $(M=5.07, S D=1.31)$, and providing intellectual stimulation $(M=5.05, S D=1.20)$. Participants also perceived a high level of support from their organization $(M=4.89$, $S D=1.08)$.

\section{Pearson Correlations}

Pearson correlation coefficients were also calculated in order to examine the relationships among the measured variables. As can be seen in Table 3, overall, openness to experience was positively and moderately correlated with creativity $(r=.48, p<.01)$. All six transformational leadership dimensions, articulating a vision $(r=.43, p<.01)$, providing an appropriate model $(r=.25, p<.01)$, fostering acceptance of group goals $(r=.30, p<.01)$, setting expectations of high performance $(r=.39, p<.01)$, giving individualized support $(r=.23, p<.01)$, and providing intellectual stimulation $(r=.41$, $p<.01$ ), were moderately and positively correlated with creativity. Among them, articulating vision, providing intellectual stimulation, and setting expectations of higher 
performance were relatively strongly correlated with creativity. POS was also positively correlated with creativity $(r=.32, p<.01)$. These results indicate that (a) the more openness to experience an individual has, (b) the more transformational leadership qualities an individual's supervisor displayed, and (c) the more an individual perceived the organization to be supportive, the higher the individual's creativity.

As can be seen in Table 3, the six transformational leadership dimensions were moderately and strongly related to each other, with articulating a vision and providing an appropriate model being the two most correlated dimensions $(r=.74, p<.01)$. In other words, the more a leader articulated a vision, the more likely the leader would also provide an appropriate model. Openness to experience was only moderately correlated with POS $(r=.21, p<.05)$ and two transformational leadership dimensions, setting expectations of high performance $(r=.26, p<.01)$ and providing intellectual stimulation $(r=.21, p<.05)$. These findings indicate that the more a person was open to new experiences, the more that person (a) perceived the organization to be supportive and (b) perceived that his or her supervisor set expectations of high performance and provided intellectual stimulation. POS was moderately correlated with all six transformational leadership dimensions, ranging from .27 to .57 . Giving individualized support was the most strongly related to POS $(r=.57, p<.01)$, indicating that the more an individual's supervisor displayed transformational leadership qualities, the more the individual perceived the organization to be supportive. 


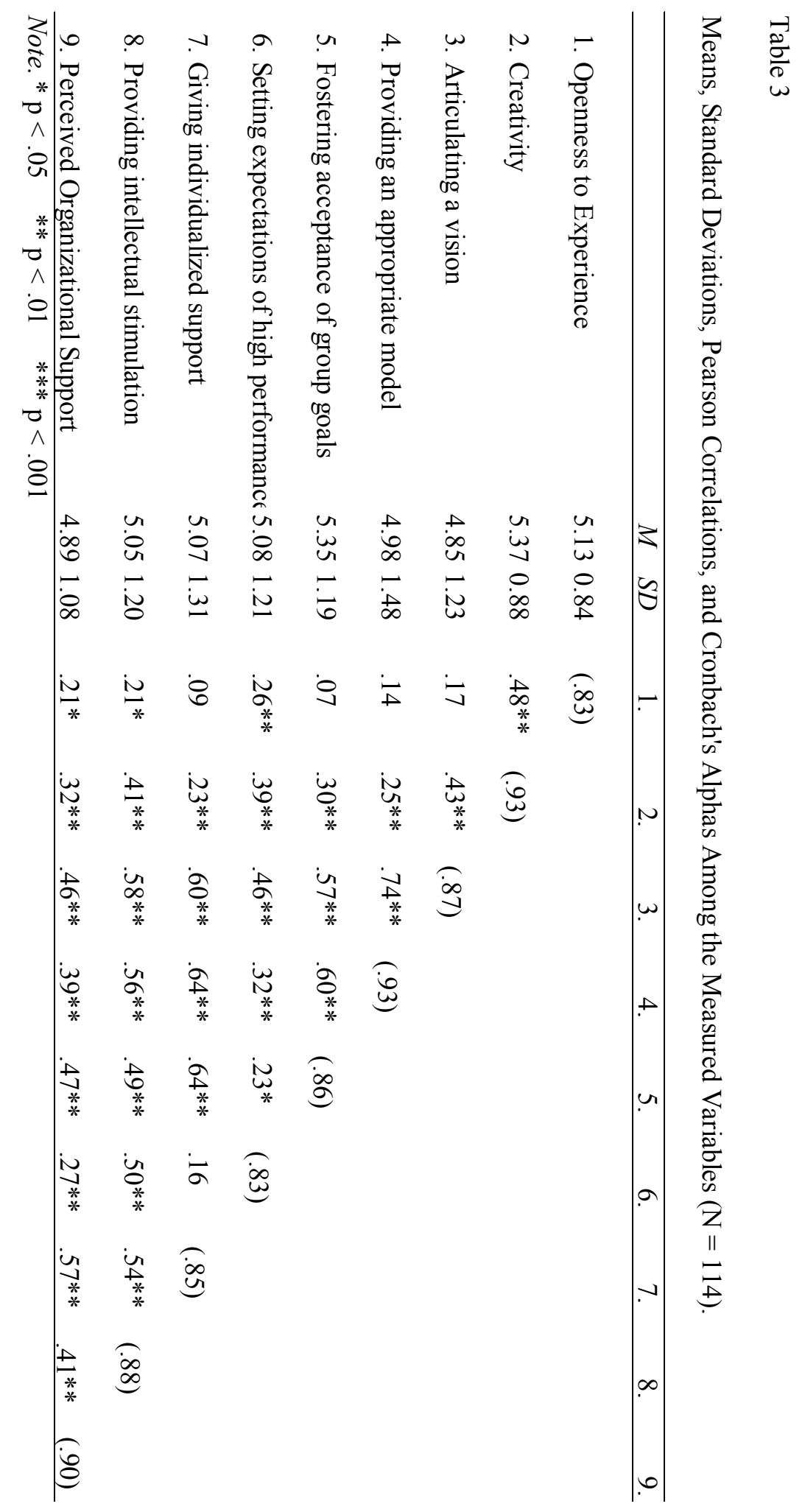




\section{Test of Hypotheses}

Hypotheses were tested using hierarchical multiple regression (MRC) analyses.

Before testing the hypotheses, openness to experience, the six transformational leadership dimensions, and POS were mean-centered.

Hypotheses 1 stated that transformational leadership would moderate the relationship between openness to experience and creativity such that the relationship would be stronger when transformational leadership is high than when transformational leadership is low. In this hierarchical regression analysis, these mean-centered variables were entered in a series of three steps: openness to experience in step one, the six transformational leadership dimensions in step two, and the cross products of openness to experience and each of the transformational leadership dimensions in step three. These six interaction terms were entered into the last step of the analysis in order to test whether or not any of the transformational leadership dimensions moderated the relationship between openness to experience and creativity. In other words, if the variance explained by any of the interaction terms was significant, it would indicate that the respective transformational leadership dimension moderated the relationship between openness to experience and creativity.

As shown in Table 4, the first step of the analysis indicated that there was a significant relationship between openness to experience and creativity $\left(\mathrm{R}^{2}=.23\right.$, $\left.\mathrm{R}^{2}{ }_{\text {adj }}=.22, \mathrm{~F}(1,112)=33.33, p<.001\right)$, suggesting that the higher one's openness to experience level, the higher one's creativity level. Openness to experience explained $23 \%$ of the variance in creativity. 
The results of the second step of the analysis showed that transformational leadership explained an additional $18 \%$ of the variance in creativity above and beyond openness to experience $\left(\Delta \mathrm{R}^{2}=.18, \mathrm{R}^{2}=.41, \mathrm{R}_{\text {adj }}^{2}=.37, \mathrm{~F}(6,106)=5.51, p<.001\right)$, indicating that the six dimensions of transformational leadership predicted one's creativity above and beyond openness to experience. However, a closer inspection of the beta weights of the six transformational leadership revealed that only articulating a vision was significantly related to creativity $(\beta=.34, p<.05)$.

In the last step of analysis, the six interaction terms did not explain a significant amount of variance above and beyond openness to experience and the six transformational leadership dimensions $\left(\Delta \mathrm{R}^{2}=.02, \mathrm{R}^{2}=.43, \mathrm{R}^{2}{ }_{\text {adj }}=.36, \mathrm{~F}(6,100)=.52\right.$, $p>.05)$, but it was not statistically significant. Therefore, results of the analysis did not support Hypothesis 1a and 1b. Transformational leadership did not moderate the relationship between openness to experience and creativity. Instead, those who were open to experience and had transformational leaders displayed more creativity on their job. 


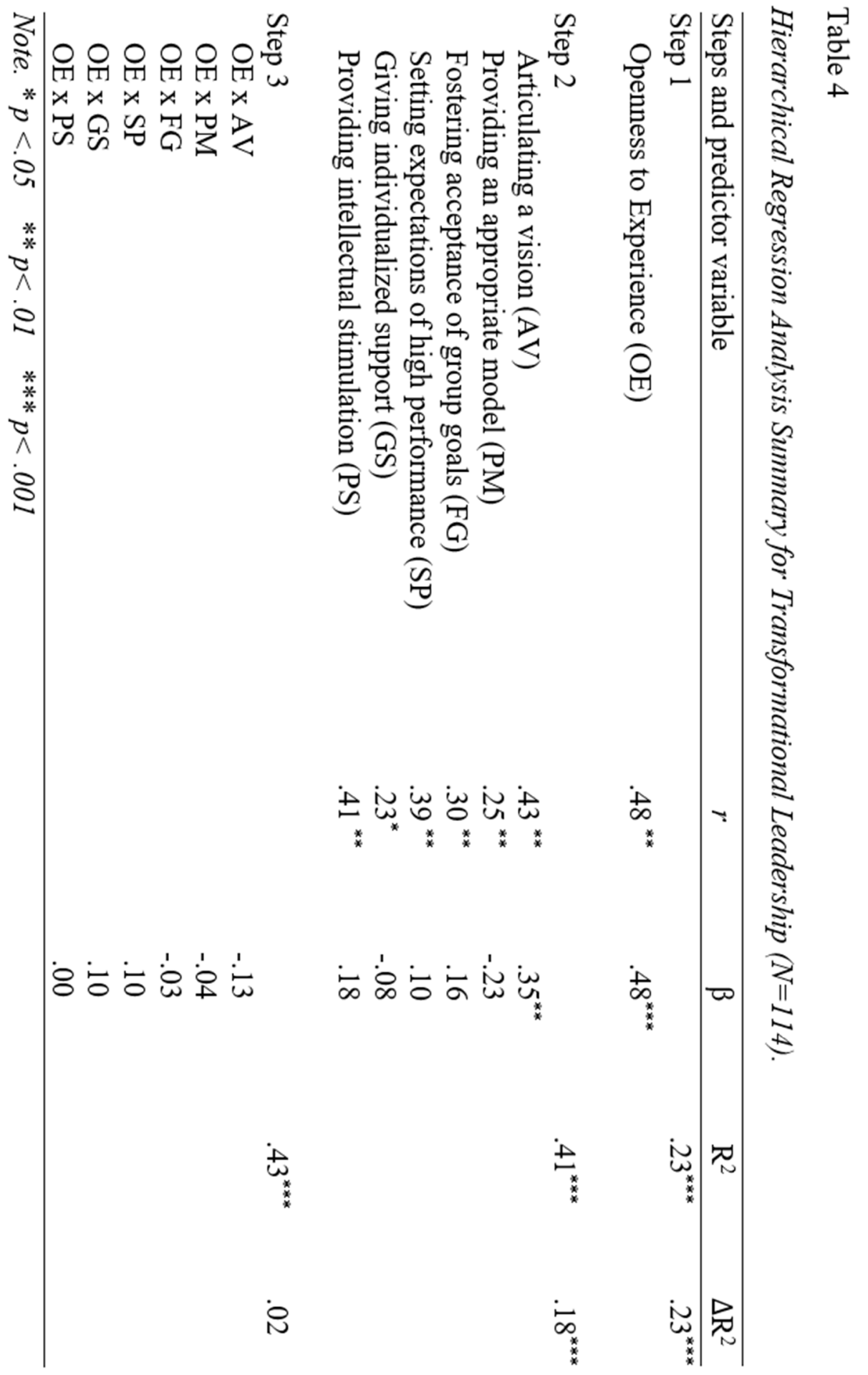


Next, I tested Hypothesis 2, which stated that POS would moderate the relationship between openness to experience and creativity such that the relationship would be stronger when POS is high than when POS is low. The mean-centered variables were entered in a series of three steps: openness to experience in step one, POS in step two, and the cross products of openness to experience and POS in step three. The interaction term was entered into the last step of the analysis in order to test whether or not POS moderated the relationship between openness to experience and creativity. In other words, if the variance explained by any of the interaction terms was significant, it would indicate that POS moderates the relationship between openness to experience and creativity.

As shown in Table 5, the first step of the analysis indicated that there was a significant relationship between openness to experience and creativity $\left(\mathrm{R}^{2}=.23\right.$, $\left.\mathrm{R}^{2}{ }_{\text {adj }}=.22, \mathrm{~F}(2,112)=33.33, p<.001\right)$, suggesting that the higher one's openness to experience, the higher one's creativity level. Openness to experience explained $23 \%$ of the variance in creativity.

The results of the second step of the analysis showed that POS explained an additional $5 \%$ of the variance in creativity above and beyond openness to experience $\left(\Delta \mathrm{R}^{2}=.05, \mathrm{R}^{2}=.28, \mathrm{R}_{\text {adj }}^{2}=.27, \mathrm{~F}(1,111)=7.66, p<.01\right)$. POS predicted one's creativity above and beyond openness to experience.

In the last step of analysis, the openness to experience by POS interaction term did not explain a significant amount of variance above and beyond openness to experience and $\operatorname{POS}\left(\Delta \mathrm{R}^{2}=.003, \mathrm{R}^{2}=.28, \mathrm{R}^{2}{ }_{\text {adj }}=.27, \mathrm{~F}(1,110)=.47, p>.05\right)$, but it was not 
statistically significant. Therefore, results of the analysis did not show support for Hypothesis $2 \mathrm{a}$ and $2 \mathrm{~b}$. POS did not moderate the relationship between openness to experience and creativity. Instead, those who were open to experience and perceived their organization to be supportive displayed more creativity on the job.

Table 5

Hierarchical Regression Analysis Summary for POS $(N=114)$.

\begin{tabular}{lcccc}
\hline Steps and predictor variable & $r$ & $\beta$ & $\mathrm{R}^{2}$ & $\Delta \mathrm{R}^{2}$ \\
\hline $\begin{array}{l}\text { Step 1 } \\
\quad \text { Openness to Experience (OE) }\end{array}$ & $.48^{* *}$ & $.43^{* * *}$ & $.23^{* * *}$ & $.23^{* * *}$ \\
& & & $.28^{* * *}$ & $.05^{* *}$ \\
$\quad$ Step 2 & $.32^{* *}$ & $.22^{* * *}$ & & \\
$\quad$ Perceived Organizational Support (TL) & & $.28^{* * *}$ & .003 \\
Step 3 & & .06 & & \\
$\quad$ OE x POS & & &
\end{tabular}

To summarize, the results of these analyses showed that the six transformational leadership interaction terms and the openness to experience by POS interaction term did not account for additional variance in an individual's creativity levels above and beyond the direct effects of openness to experience, the six transformational leadership dimensions, and POS; therefore, transformational leadership and POS did not moderate the relationship between openness to experience and creativity. However, those who were high in openness to experience, had transformational leaders who articulated a vision, and perceived their organizations to be supportive were more likely to display a higher creativity level. 


\section{Discussion}

Creativity has grown as a research topic in the literature due to its close relation to innovation, a work outcome that organizations are interested in because of its role in improving a company's long-term performance (Klijn \& Tomic, 2010). Because organizations are interested in this positive outcome, closer attention has been devoted to uncovering many different ways to increase an employee's creativity levels. Although research has shown that the personality trait, openness to experience, is strongly and positively related to creativity (Furnham et al., 2009), organizations are seeking ways in which they can alter the organizational environment in order to encourage creativity among employees. Research has supported the notion that organizational factors such as leadership style (Jung, 2001) and POS (Amabile et al., 1996) are positively related to creativity. However, few studies have been conducted to examine if these two variables could act as moderators. Woodman et al. (1993) developed the interactionist model of organizational creativity, which posited that creative behavior is a function of the interaction between an individual's predisposition and the environment. Based on this model, the present study examined whether the relationship between openness to experience and creativity could be influenced by transformational leadership and POS.

Hypothesis 1 stated that transformational leadership would moderate the relationship between openness to experience and creativity such that the relationship would be stronger when transformational leadership is high than when it is low. Results showed that openness to experience was positively related to creativity. Furthermore, transformational leadership, in particular articulating visions, predicted creativity above 
and beyond openness to experience. However, transformational leadership did not moderate the relationship between openness to experience and creativity. Thus, Hypotheses 1 was not supported. These results indicate that the higher an individual's openness to experience was and the more transformational leadership qualities the individual's supervisor displayed, the higher the individual's creativity levels; however, the relationship between openness to experience and creativity did not change as a function of the level of transformational leadership.

Lack of a significant interaction between openness to experience and transformational leadership might be due to several reasons. For example, Judge, Bono, Illies, and Gerhardt (2002) found that openness to experience was positively associated with leadership effectiveness such that the more openness to experience an individual possessed, the more a leader's performance influenced and guided the individual towards a goal. If these findings hold true, in the present study, those low in openness to experience were less likely to be influenced by a transformational leader; therefore, they did not show increased creativity even in the presence of a transformational leader. Results of the current study also found that participants who were high in openness to experience did not experience decreased creativity in the absence of a transformational leader. This may be due to the highly individualistic nature of those who are open to experience (Lun \& Bond, 2006). Their independent, self-reliant, unconventional nature propels them to actively engage with novelty despite environmental influences.

These results also indicate that transformational leadership predicts creativity, which is consistent with past findings. Additionally, results suggest that of the six 
transformational leadership dimensions, articulating a vision was the most significant predictor of creativity levels above and beyond the effect of openness to experience; in other words, when supervisors articulated a vision that was both appealing and inspiring to followers, employees were more likely to exhibit creative behavior. This is consistent with the concept of creative restraints, which states that, contrary to what many believe, limitations and constraints rather than unlimited options and a lack of rules facilitate creativity (Rosso, 2014). Research on creativity supports the notion that when options are limited, people generate a greater variety of solutions due to attention being focused rather than scattered. Therefore, when leaders articulate a specific vision, they narrow the scope of possibilities by pointing individuals towards a certain direction, providing an explicit starting point, and helping individuals exercise more focused attention.

Hypothesis 2 stated that POS would moderate the relationship between openness to experience and creativity such that the relationship would be stronger when POS is high than when POS is low. Results showed that openness to experience was positively related to creativity. Furthermore, POS predicted creativity above and beyond openness to experience. However, POS did not moderate the relationship between openness to experience and creativity. Thus, Hypotheses 2 was not supported. These results indicate that the higher an individual's openness to experience was and the more supportive the individual perceived the organization to be, the higher the individual's creativity levels; however, the relationship between openness to experience and creativity did not change as a function of one's POS. 
Participants who were low in openness to experience did not experience enhanced creativity when they perceived more organizational support. There is less research regarding the influences of POS on different personality types, but it is possible that those who are open to experience may be more willing to try and accept the different types of support provided by an organization. For example, organizations provide support through a multitude of ways, such as mentor programs where a more experienced employee provides support and guidance for new employees. Those who are high in openness to experience may be more willing to try this program despite never having a mentor before, whereas those who are low in openness to experience may be more close-minded to the idea of having a mentor. Therefore, those who are low in openness to experience may be less influenced by POS. Results also found that participants who were high openness in experience did not experience decreased creativity when POS was low. Again, the highly individualistic nature of those who are open to experience may make them more willing to engage in novel and creative pursuits despite environmental influences (Lun \& Bond, 2006).

The finding that openness to experience predicted creativity is consistent with past research; those who are open to experience possess a mindset that facilitates the conception of novel ideas due to their large range of experience as well as their tendency to hold unconventional ideas (Costa \& McCrae, 1992). Also consistent with past research, results supported showed that POS predicted creativity. According to Yu and Frenkel (2013), POS contributes to creativity through two mechanisms: group identification and outcome expectancy. Employees are more creative when they (a) feel a 
sense of identification with their organization, which fulfills needs of relatedness and autonomy, and (b) trust that their organization will properly compensate them for their hard work. These mechanisms seem to increase creativity within all employees, regardless of their openness to experience level.

\section{Theoretical Implications}

The purpose of this study was to better understand different organizational factors that could be altered in order to encourage creativity among employees. However, the results of the present study showed that transformational leadership and POS did not moderate the relationship between openness to experience and creativity. According to the Interactionist Model of Organizational Creativity (Woodman et al., 1993), environmental factors should work in conjunction with personality in order to produce a certain behavior. Relating this model to the present study, the manifestation of creative behavior should be contingent on the presence or absence of organizational factors such as transformational leadership and POS despite a person's predisposition to creativity. However, the results of this study did not support this model

Although there exists plenty research exploring which organizational factors are related to creativity, there is a lack of research exploring the impact of these organizational factors on the relationship between personality and creativity. Woodman et al. (1993) highlighted this need by stating that the understanding of organizational creativity would inevitably involve the understanding of (a) the creative process, (b) the creative product, (c) the creative person, (d) the creative situation, and (e) the way in which these four factors work together in order to produce an outcome. Although 
research has addressed the four individual components, research regarding the interaction among these components remains scarce. Thus, one implication of this study is that there needs to be further research that examines other organizational factors as moderators of the relationship between creative personality and creativity in order to expand and better understand existing models such as the interactionist model of organizational creativity.

Additionally, the number of dimensions within transformational leadership has been a subject of controversy among researchers (Podsakoff et al., 1990). Results of the factor analysis supported Podsakoff et al.’s (1990) conceptualization of transformational leadership, which states that transformational leadership consists of six dimensions: articulating a vision, providing an appropriate model, fostering acceptance of group goals, setting expectations of high performance, giving individualized support, and providing intellectual stimulation. Furthermore, articulating a vision was the most significant predictor of creativity levels above and beyond the effect of openness to experience. This new finding adds to existing leadership literature by highlighting which specific dimension of transformational leadership contributes to creativity. However, the reason why other dimensions did not predict creativity might have been because these dimensions are relatively highly correlated with each other. The present study also showed that transformational leadership had a stronger effect on creativity than POS.

\section{Practical Implications}

Although the findings of this study did not support the moderating effect of transformational leadership and POS on the relationship between openness to experience and creativity, it showed that transformational leadership and POS are significant 
predictors of creativity above and beyond the effect of openness to experience. The predictive nature of these two organizational factors is consistent with findings within the current creativity literature (Jung, 2001; Amabile et al., 1996). Additionally, the results of this study highlighted which component of transformational leadership impacted creativity the most.

If organizations wish to increase creative behavior among employees, in addition to selecting individuals with a creative predisposition (i.e., high openness to experience), increased focus should be directed towards developing a culture in which employees feel supported and implementing programs that provide employees with resources they need to efficiently complete their job and manage stressful situations. Programs should focus on addressing the socio-emotional needs of workers. For example, perhaps implementing a mentor program within an organization would reduce the perceived amount of stress that is often the result of starting a new position. New employees would be paired with a mentor who is trained to provide not only psychological and emotional support, but also providing practical support involving job duties. As a result, the new employee would feel a sense of support from the organization. Additionally, because the findings of the present study show that a leader's ability to articulate a vision is the strongest predictor (of the six transformational leadership dimensions) of creativity, organizations can implement a program that helps supervisors develop behaviors that are associated with transformational leadership, with a special focus on managers being able to clearly and successfully articulate an inspiring vision to employees. 


\section{Limitations of the Study and Future Research}

The present study has several limitations pertaining to design and methodology. Firstly, the method in which I collected the data involved contacting individuals through my personal and professional networks. Because the majority of the participants were under the age of 35, my sample was heavily skewed towards this age group; therefore, my sample did not properly reflect the working population and therefore may have affected my results.

For example, as one might expect, the younger an individual is, the less likely that this individual has worked at an organization for an extended period of time. As such, nearly half of the participants worked at their organization for under a year $(43.9 \%)$, and $29.8 \%$ worked at their organization for 1-3 years. The limited variability of tenure undoubtedly affected the variability of responses. In a study regarding POS and job involvement, Gorji, Etemadi, and Hoseini (2014) found a positive relationship between POS and age and tenure, suggesting that the older an individual was and the longer the individual had worked at an organization, the more support the individual perceived from the organization. When an individual has worked at an organization for a prolonged period, the individual has more time to bond his own identity with and feel a sense of relatedness to the organization (Taleghani, 2009). Because the majority of participants were below the age of 35 and worked at their organization for under 3 years, results regarding POS may have been affected. According to my data, POS was slightly positively skewed, indicating that my participants perceived less organizational support 
than average. Future research should focus on gathering a sample that is more representative of the population by utilizing more varied data collection methods.

Secondly, a self-report questionnaire was used to gather data due to cost efficiency and ease of distribution; however, this can be problematic in a couple of ways. People are often subject to a variety of biases when answering questions from their own perspective, including the response bias, an individual's tendency to respond in a certain way despite evidence that suggests otherwise (Austin, Gibson, Deary, McGregor, \& Dent, 1998), and social desirability bias, the tendency to answer in a manner that would be perceived as socially acceptable (Phillips \& Clancy, 1972). This type of systematic error is known as the common method variance; in other words, variations within responses are attributed to the measurement instrument rather than to an individual's predisposition (Podsakoff, MacKenzie, \& Lee, 2003).

Method biases are the most common source of measurement error, which threatens the validity of conclusions drawn from analyses (Nunnally, 1978). Because all variables were measured using a self-report questionnaire, results were subject to these aforementioned biases. Relating this method bias to my study, participants may have inaccurately exaggerated their creativity and/or openness to experience levels because they perceived these traits as socially desirable. Additionally, participants may have felt subconsciously pressured to represent their organization in a favorable light, resulting in responses that exaggerate their perception of support from organizations and/or the amount of transformational leadership qualities possessed by their supervisor. In the future, multiple methods of measurements should be used in order to decrease the impact 
of common method variance. Gathering creativity and personality data from employees as well as their peers and supervisors would provide a more holistic and therefore accurate view of the employee.

The measure of creativity also may not have been relevant to my participants depending on their position. For example, jobs that are routine or only require a small range of skills to complete (i.e. a cashier) would allow little room for employees to display creativity due to the narrow scope and repetitive nature of the job. Because my sample largely consisted of college-aged individuals, many participants worked as truckers, cashiers, waitresses, and other repetitive jobs. In the future, perhaps participants should be selected only if their position allows for the display of creativity, or another measurement could be added to account for the level of routineness within a job.

Lastly, the absence of an interaction effect might be due to the lack of statistical power. My sample only consisted of 114 participants due to a large dropout rate. Perhaps if I had a larger sample size, I may have found an interaction effect.

\section{Conclusion}

Given the increased need to compete within a rapidly growing global market, creativity and innovation are important topics for organizations to fully understand. Organizations strive to reap the positive outcomes that are associated with creativity; thus, research has examined different factors that influence employee creativity, such as transformational leadership and POS. However, previous research has limited focus on how the absence or presence of organizational factors may influence the relationship between one's predisposition and creativity levels. Therefore, the purpose of the present 
study was to address this gap in the literature and provide insight into how transformational leadership and POS could impact the manifestation of creative behavior along with a person's predisposition towards creativity.

Results revealed that although neither of the two organizational factors moderated the relationship between openness to experience and creativity, both were significant predictors of creativity above and beyond the effect of openness to experience, which is consistent with findings in extant literature. Additionally, this study added to the current literature by pinpointing which transformational leadership dimension most strongly predicted creativity: articulating a vision. Additional research is needed to further understand the ways in which transformational leadership and POS may interact with personality to impact creativity.

Although results of the current study did not support the interactionist model of organizational creativity, it did reveal the positive relationship between openness to experience, transformational leadership (particularly articulating a vision), and POS and creativity. Also, there assuredly exists other unknown organizational factors that can be altered in order to enhance creativity within those who are not predisposed to being creative. The number of organizational factors that have yet to be studied in relation to creativity is vast, and our understanding of the way personality and organizational factors interact is at its infancy. Perhaps all that is required to further expand our understanding of organizational creativity is a relentless drive to explore the unknown combined with a dash of creativity. 


\section{References}

Allen, S. L., Smith, J. E., Da Silva, N. (2013). Leadership style in relation to organizational change and organizational creativity: Perceptions from nonprofit organizational member. Nonprofit Management and Leadership, 24, 23-42.

Amabile, T. M. (1983). Social psychology of creativity: A componential conceptualization. Journal of Personality and Social Psychology, 45, 997-1013.

Amabile, T. M. (1988). A model of creativity and innovation in organizations, Research in Organizational Behavior, 10, 123-167.

Amabile, T. M. (1988). Creativity in context. Boulder, CO: Westview Press.

Amabile, T. M., Conti, R., Coon, H., Lazenby, J., \& Herron, M. (1996). Assessing the work environment for creativity. Academy of Management Journal, 39, 1154-1184.

Ashforth, B. E., \& Mael, F. A. (1989). Social identity theory and organization. The Academy of Management Review, 14, 20-39.

Austin, E. J., Deary, I. J., Gibson, G. J., McGregor, M. J., \& Dent, J. B. (1988). Individual responses spread in self-report scales: Personality correlations and consequences. Personality and Individual Differences, 24, 421-438.

Bammens, Y., Notelaers, G., \& Van Gils, A. (2013). Employee as a source of innovation: The role of perceived organizational support in family firms. Academy of Annual Meeting, 2013, 89-94.

Barrick, M.R., \& Mount, M.K. (1993). Autonomy as a moderator of the relationship between the Big Five personality dimensions and job performance. Journal of Applied Psychology, 78, 111-118.

Barron, F., \& Harrington, D. M. (1981). Creativity, intelligence, and personality. Annual Review of Psychology, 32, 439-476.

Bass, B. M. (1985). Leadership and performance beyond expectations. New York: Free Press.

Bass, B. M. (1988). Transformational leadership: Industry, military, and educational impact. Mahwah, NJ: Erlbaum.

Batey, M., Chamorro-Premuzic, T., \& Furnham, A. (2009). Intelligence and personality as predictors of divergent thinking: the role of general, fluid and crystallised intelligence. Thinking Skills and Creativity, 4, 60-69. 
Batey, M., \& Furnham, A. (2006). Creativity, intelligence, and personality: A critical review of the scattered literature. Genetic, Social, and General Psychology Monographs, 132, 355-429.

Batey, M., Furham, A., \& Safiullina, X. (2010). Intelligence, general knowledge and personality as predictors of creativity. Learning and Individual Differences, 20, 532-535.

Bennis, W., \& Nanus, B. (1985). Leadership: The strategies for taking charge. New York, NY: Harper \& Row.

Carmeli, A., Sheaffer, Z., Binyamin, G., Reiter-Palmon, R., \& Shimoni, T. (2014). Transformational leadership and creative problem-solving: The mediating role of psychological safety and reflexivity. The Journal of Creative Behavior, 48, 115-135.

Carson, S. H., Peterson, J. B., \& Higgins, D. M. (2005). Reliability, validity, and factor structure of the creative achievement questionnaire. Creativity Research Journal, 17, 37-50.

Chamarro-Premuzic, T., \& Reichenbacher, L. (2008). Effects of personality and threat of evaluation on divergent and convergent thinking. Journal of Research in Personality, 42, 1095-1101.

Clark, K., \& James, K. (1999). Justice and positive and negative creativity. Creativity Research Journal, 3(12), 311-320.

Cohen, G. (2005). The mature mind: The positive power of the aging brain. New York, NY: Basic Books.

Cohen-Meitar, R., Carmeli, A., Waldman, D.A. (2009). Linking meaningfulness in the workplace to employee creativity: The intervening role of organizational identification and positive psychological experiences. Creativity Research Journal, 21, 361-375.

Costa, P. T. \& McCrae, R. R. (1992). Revised NEO Personality Inventory (NEO-PI-R) and NEO Five Factor Model (NEO-FFI) professional manual. Odessa, FL: Psychological Assessment Resources.

Davis-Blake, A., \& Pfeffer, J. (1989). Just a mirage: The search for dispositional effects in organizational research. Academy of Management Review, 14, 385-400.

De Jong, J., Den Hartog, D., \& Zoetermeer (2003). Leadership as a determinant of innovative behavior: A conceptual framework. Research report H200303, I-95. 
Deci, F. L., \& Ryan, R. M. (1980). The empirical exploration of intrinsic motivational processes. In L. Berkowitz (Ed.), Advances in experimental social psychology (pp. 39-80). New York, NY: Academic Press.

Donaldson, S. I., \& Ko, I. (2010). Positive organisational psychology, behavior, and scholarship: A review of the emerging literature and evidence base. The Journal of Positive Psychology, 5, 177-191.

Eisenberger, R., \& Stinglhamber, F. (2011). Perceived organizational support: Fostering enthusiastic and productive employees. Washington, DC: American Psychological Association.

Endler, N.S., \& Magnusson, D. (1976). Toward an interactional psychology of personality. Psychological Bulletin, 83, 956-974.

Feist, G. J. (1998). A meta-analysis of personality in scientific and artistic creativity. Personality and Social Psychology Review, 2, 290-309.

Furnham, A., \& Bachtiar, V. (2008). Personality and intelligence as predictors of creativity. Personality and Individual Differences, 45, 613-617.

Furnham, A., Batey, M., Anand, K., \& Manfield, J. (2008). Personality, hypomania, intelligence and creativity. Personality and Individual Differences, 44, 1060-1069.

Furnham, A., Crump, J., Batey, M., \& Chamorro-Premuzic, T. (2009). Personality and ability predictors of the "consequences" test of divergent thinking in a large nonstudent sample. Personality and Individual Differences, 46, 536-540.

George, J. M., Reed, T. F., Ballard, K. A., Colin, I., \& Fielding, I. (1993). Contact with AIDS patients as a source of work-related distress: Effects of organizational and social support. Academy of Management Journal, 36, 157-171.

George, J. M., \& Zhou, J. (2007). Dual tuning in a supportive context: Joint contributions of positive mood, negative mood, and supervisory behaviors to employee creativity. Academy of Management Journal, 50, 605-622.

Gorji, H.A., Etemadi, M., \& Hoseini, F. (2014). Perceived organizational support and job involvement in the Iranian health care system: A case study of emergency room nurses in general hospitals. Journal of Education and Health Promotion, 3, 58.

Gouldner, A. W. (1960). The norm of reciprocity: A preliminary statement. American Sociology Review, 25, 161-178. 
Gumusluoglu, L., \& Ilsev, A. (2009). Transformational leadership and organizational innovation: The roles of internal and external support for innovation. Journal of Business Research, 62, 461-273.

Herrmann, D., \& Felfe, J. (2013). Moderators of the relationship between leadership style and employee creativity: The role of task novelty and personal initiative. Creativity Research Journal, 25, 172-181.

Heslin, P. A. (2005). Conceptualizing and Evaluating Career Success. Journal of Organizational Behavior, 6, 113-116.

Hunter, S. T., Bedell, K. E., \& Mumford, M. D. (2007). Climate for creativity: A quantitative review. Creativity Research Journal, 19, 69-90.

Jaiswal, N. K. \& Dhar, R. L. (2015). Transformational leadership, innovation climate, creative self-efficacy and employee creativity: A multilevel study. International Journal of Hospitality Management, 51, 30-41.

Jaussi, K., \& Dionne, S. (2003). Leading for creativity: The role of unconventional leader behavior. The Leadership Quarterly, 14, 475-498.

Judge, T. A., Bono, J. E., Illies, R., \& Gerhardt, M. W. (2002). Personality and leadership: A qualitative and quantitative review. Journal of Applied Psychology, 87, 765-780.

Judge, T. A., \& Piccolo, R. F. (2004). Transformational and transactional leadership: A meta-analytic test of their relative validity. Journal of Applied Psychology, 89, 755-768.

Jung, D. (2001). Transformational and transactional leadership and their effects on creativity in groups. Creativity Research Journal, 13, 185-195.

Jung, D., \& Avolio, B. (2000). Opening the black box: An experimental investigation of the mediating effects of trust and value congruence on transformational and transactional leadership. Journal of Organizational Behavior, 21, 949-964.

Jung, D. I., Chow, C., \& Wu, A. (2003). The role of transformational leadership in enhancing organizational innovation: Hypotheses and some preliminary findings. The Leadership Quarterly, 14, 525-544.

Kandler, C., Rainer, R., Angleitner, A., Spinath, F. M., Borkenau, P., \& Penke, L. (2016). The nature of creativity: The roles of genetic factors, personality traits, cognitive abilities, and environmental sources. Journal of Personality and Social Psychology, 111, 230-249. 
Kahai, S. S., Sosik, J. J., \& Avolio, B. J. (2003). Effects of leaderships style, anonymity, and rewards of creativity-relevant processes and outcomes in an electronic meeting system context. Leadership Quarterly, 14, 499-524.

Khazanchi, S., \& Masterson, S. S. (2011). Who and what is fair matters: A multi-foci social exchange model of creativity. Journal of Organizational Behavior, 32, 86-106.

Klijn, M., \& Tomic, W. (2010). A review of creativity within organizations from a psychological perspective. Journal of Management Development, 29, 322-343.

Lewin, K. (1940). Formalization and progress in psychology. In K. Lewin (Ed.), Field theory in social science (pp. 1-29). New York: Harper \& Row.

Lun V. M.-C., Bond M. H. (2006). Achieving relationship harmony in groups and its consequence for group performance. Asian Journal of Social Psychology, 9, 195-202.

McCrae, R. R. (1996). Social consequences of experiential openness. Psychological Bulletin, 120, 323-337.

McCrae, R. R. \& Costa, P. T. (1997). Personality trait structure as human universal. American Psychologist, 52, 509-516.

Mead, G. H. (1934). Mind, Self, and Society. Chicago: Univ. Chicago Press.

Moghimi, S., \& Subramaniam, I. D. (2013). Employee's creative behavior: The role of organizational climate in Malaysian SMEs. International Journal of Business and Management, 8, 1-12.

Nunnally, J. C. (1978). Psychometric theory (2nd ed.). New York: McGraw-Hill.

Nusair, N., Ababneh, R., \& Bae, Y. K. (2012). The impact of transformational leadership style on innovation as perceived by public employees in Jordan. International Journal of Commerce and Management, 22, 182-201.

Oldham, G., \& Cummings, A. (1996). Employee Creativity: Personal and contextual factors at work. Academy of Management Journal, 39, 607-634.

Phillips, D. L., \& Clancy, K. J. (1972). Some effects of "social desirability" in survey studies. American Journal of Sociology, 77, 921-940.

Podsakoff, P. M., MacKenzie, S. M., Lee, J., \& Podsakoff, N. P. (2003). Common method variance in behavioral research: A critical review of the literature and recommended remedies. Journal of Applied Psychology, 88, 879-903. 
Podsakoff, P. M., MacKenzie, S. B., Moorman, R. H., \& Fetter, R. (1990). Transformational leader behaviors and their effects on followers' trust in leader, satisfaction, and organizational citizenship behaviors. Leadership Quarterly, 1, 107-142.

Rhoades, L., \& Eisenberger, R. (2002). Perceived organizational support: A review of the literature. Journal of Applied Psychology, 87, 698-714.

Rosso, B. D. (2014). Creativity and constraints: Exploring the role of constraints in the creative processes of research and development teams. Organization Studies, 35, 551-585.

Sawyer, K. R. (2012). Explaining creativity: The science of human innovation (2nd ed.). New York, NY: Oxford University Press.

Scott, S. G., \& Bruce, R. A. (1994). Determinants of innovative behavior: A path model of individual innovation in the workplace. The Academy of Management Journal, 37, 580607.

Sheldon, K. M., \& Elliot, A. J. (1998). Not all personal goals are personal: Comparing autonomous and controlled reasons for goals as predictors of effort and attainment. Personality and Social Psychology Bulletin, 24, 546-557.

Shin, S. J., \& Zhou, J. (2003). Transformational leadership, conservation, and creativity: Evidence from Korea. Academy of Management Journal, 46, 703-714.

Sternberg, R. J. (2006). The nature of creativity. Creativity Research Journal, 18, 87-98.

Thaleghani, G., Divandari, A., Shirmohammadi, M. (2009). Impact of perceived organisational support on commitment employee and organisational performance: Case study of Mellat Bank Brenches in Tehran. J Iran Manage Science, 16, 1-25.

Wiggins, J. S., \& Trapnell, P. D. (1997). Personality structure: The return of the big five. In R. Hogan, J. Johnson, \& S. Briggs (Eds.), Handbook of personality psychology (pp. 737765). San Diego: Academic Press.

Woodman, R. W., Sawyer, J. E., \& Griffin, R. W. (1993). Toward a theory of organizational creativity. Academy of Management Review, 18, 293-321.

Yu, C., \& Frenkel, S. J. (2013). Explaining task performance and creativity from perceived organizational support theory: Which mechanisms are important? Journal of Organizational Behavior, 34, 1165-1181. 
Yunus, N. H., \& Anuar, S. R. (2012). Trust as moderating effect between emotional intelligence and transformational leadership styles. Interdisciplinary Journal of Contemporary Research in Business, 3, 650-663.

Zhou, J., \& George, J.M. (2001). When openness to experience and conscientiousness are related to creative behavior: An interactional approach. Journal of Applied Psychology, $86,513-524$. 


\section{Appendix}

\section{Survey Questions}

\section{Creativity}

1. I will suggest new ways to achieve goals or objectives.

2. I will come up with new and practical ideas to improve performance.

3. I will search out new technologies, processes, techniques, and/or product ideas.

4. I will suggest new ways to increase quality.

5. I am a good source of creative ideas.

6. I am not afraid to take risks.

7. I will promote and champion ideas to others.

8. I will exhibit creativity on the job when given.

9. I will develop adequate plans and schedules for the implementation of new ideas.

10. I often have new and innovative ideas.

11. I will come up with creative solutions to problems.

12. I often have a fresh approach to problems.

13. I will suggest new ways of performing tasks.

\section{Transformational Leadership}

14. Has a clear understanding of where we are going.

15. Paints an interesting picture of the future for our group.

16. Inspires others with his/her plans for the future.

17. Is able to get others committed to his/her dream.

18. Leads by "doing," rather than simply by "telling."

19. Provides a good model for me to follow.

20. Leads by example.

21. Encourages employees to be "team players."

22. Gets the group to work together for the same goal.

23. Develops a team attitude and spirit among employees.

24. Shows us that he/she expects a lot from us.

25 . Insists on only the best performance.

26. Will not settle for second best.

27. Acts without considering my feelings. *

28. Shows respect for my personal feelings.

29. Behaves in a manner thoughtful of my personal needs.

30. Challenges me to think about old problems in new ways.

31. Asks questions that prompt me to think.

32. Has stimulated me to rethink the way I do things.

33. Has ideas that have challenged me to re-examine some of the basic assumptions about my work. 
Perceived Organizational Support

34. My organization considers my goals and values.

35. My organization really cares about my well-being.

36. My organization shows little concern for me.*

37. My organization would forgive an honest mistake on my part.

38. My organization cares about my opinion.

39. If given the opportunity, my organization would take advantage of me. *

40. Help is available from my organization when I have a problem.

41. My organization is willing to help me when I need a special favor.

\section{Openness to Experience}

42. Is original and comes up with new ideas.

43. Is curious about many different things.

44. Is ingenious, a deep thinker.

45. Has an active imagination.

46. Is inventive.

47. Values artistic, aesthetic experiences.

48. Prefers work that is routine. *

49. Likes to reflect, play with ideas.

50. Has few artistic interests. *

51. Is sophisticated in art, music, or literature.

* Indicates that survey questions were reverse scored 